\title{
Crack Growth Behavior of Al Alloy 7075-T6 under Ultrasonic Fatigue*
}

\author{
Qiang CHEN **, Norio KAWAGOISHI ***, Masahiro OKI**, \\ Masahiro GOTO**** and Qingyuan WANG***** \\ ${ }^{* *}$ Kochi National College of Technology, \\ 200-1 Monobe, Nankoku, 783-8508, Japan \\ E-mail: qchen@me.kochi-ct.ac.jp \\ ***Faculty of Engineering, Kagoshima University, \\ 1-21-40 Korimoto, Kagoshima, 890-0065, Japan \\ E-mail: hiro@mech.kagoshima-u.ac.jp \\ ****Faculty of Engineering, Oita Univeraity, \\ 700 Dannoharu, Oita-shi, 870-1192 Japan \\ ${ }^{* * * \star *}$ College of Architecture and Environment, Sichuan University, \\ Chengdu 610065, China
}

\begin{abstract}
In order to investigate the effect of loading frequency on crack growth behavior, ultrasonic fatigue and rotating bending fatigue tests were carried out for an extruded age-hardened Al alloy 7075-T6 in ambient air and in $\mathrm{N}_{2}$ gas. Fatigue strength increased in ultrasonic fatigue due to the retardation of crack initiation and its early propagation. In ultrasonic fatigue, however, crack growth transition took place from tensile mode to shear mode when cracks grew faster than $\sim 3 \times 10^{-9}$ $\mathrm{m} /$ cycle. As a result, macroscopic crack paths changed from nearly vertical to stress axis to oblique $\sim 35$ degrees against the axis. Fracture mechanism involved in ultrasonic fatigue also changed from striations featured to transgranular facets characterized with microscopic voids. The relation between the applied stress, $\sigma_{\mathrm{a}}$, and the crack depth at the crack growth transition, $b_{\mathrm{T}}$, can be expressed as $\sigma_{\mathrm{a}}{ }^{\mathrm{n}} b_{\mathrm{T}}=$ constant. The results were discussed from the viewpoints of time dependent environmental effect and the texture of the alloy.
\end{abstract}

Key words: Fatigue, Ultrasonic, Age-Hardened Al-Alloy, Crack Growth, Fracture Mechanism, Environmental Effect, Texture

\section{Introduction}

Recently, the increasing requirements of economic development and the reduction in environment burdens demand for the immediate investigations of the very high cycle fatigue properties in metallic materials for the purpose of gigacycle fatigue life design and the estimation of the integrity of ageing machines and structures. Many researches were performed by focusing on high strength steels and surface hardened steels. For example, internal fracture took place at stress levels lower than the conventional fatigue limit and beyond $10^{7}$ cycles, leading to characteristic step-wise endurance curves ${ }^{(1)-(4)}$. The mechanisms involved in the internal fracture, however, have not been clarified yet. On the other hand, fatigue tests in gigacycle regime are usually time-consuming and expensive to conduct. Ultrasonic fatigue methodology was introduced as an accelerated testing tool that has now found extensive applications in exploring ultra long life fatigue strength for various kinds of metals ${ }^{(5)-(16)}$. However, the validity of ultrasonic fatigue methodology or the effect of ultrasonic frequency on fatigue properties has not yet been completely understood. For

"Received 24 July, 2008 (No. T1-06-0096) Japanese Original : Trans. Jpn. Soc. Mech. Eng., Vol. 72, No. 721, A (2006) pp.1356-1363 (Received 30 Jan., 2006) [DOI: 10.1299/jcst.2.1399] 
example, Bathias ${ }^{(5)(6)}$ and Tschegg ${ }^{(7)}$ found no significant difference in fatigue strength for many metals subjected to ultrasonic and conventional fatigue. Little influence of ultrasonic cyclic deformation on fatigue strength was also reported in a bearing steel SNCM439 ${ }^{(8)}$ and a Ti based alloy ${ }^{(9)}$, in which failure occurred from substrate inclusions and/or matrix cracking. When the metals fractured from surface cracking, however, fatigue strength of plain specimens increased remarkably under ultrasonic cyclic loading, while the rise in fatigue strength of notched specimens was not obvious ${ }^{(8)(9)}$. The effect of loading frequency on fatigue strength was then explained in terms of the relation between dislocation gliding velocity and strain rate ${ }^{(9)}$.

In our recent studies on nickel based superalloy Inconel $718^{(10)(11)}$, ultrasonic cycling affected the fatigue behavior of the alloy in such a way that fatigue strength of a plain specimen increased under ultrasonic cycling while that of a notched one decreased reversely. It was reported that even ambient environment could affect fatigue strength of high strength alloys ${ }^{(12)-(15)}$, implying the importance of interaction between ambient air and fatigue cracks. On the other hand, non-ferrous metallic alloys usually do not show distinct fatigue limit and their behavior in gigacycle fatigue was not well understood. In the previous study on Al alloy 7075-T6 ${ }^{(16)}$, for example, strength was higher under ultrasonic fatigue than under rotating bending fatigue, and crack growth mode transited from tension to shear during ultrasonic fatigue. However, the fracture mechanism included in ultrasonic fatigue has not yet been clarified.

The objective of the present study, therefore, is to investigate the effect of ultrasonic frequency on the fatigue crack growth behavior of age-hardened Al alloy 7075-T6 in ambient air and in $\mathrm{N}_{2}$ gas. The fracture mechanism involved in ultrasonic fatigue will be examined through subsequent surface observation and scanning electron microscopic analysis.

\section{Material and Experimentals}

The material used was an extruded bar of age-hardened Al alloy 7075-T6. The chemical composition (wt. \%) is $0.09 \mathrm{Si}, 1.47 \mathrm{Cu}, 0.25 \mathrm{Fe}, 0.03 \mathrm{Mn}, 2.56 \mathrm{Mg}, 0.19 \mathrm{Cr}, 5.46 \mathrm{Zn}, 0.03 \mathrm{Zr}$, $0.03 \mathrm{Ti}$, and the remainder $\mathrm{Al}$. The mechanical properties are $630 \mathrm{MPa}$ of $0.2 \%$ proof stress, $691 \mathrm{MPa}$ of tensile strength, $764 \mathrm{MPa}$ of true fracture strength, and $9.5 \%$ of reduction in area, respectively. Fig. 1 shows shape and dimensions of (a) ultrasonic and (b) rotating bending fatigue specimens. All of the specimens were electrochemically polished by 20 $\mu \mathrm{m}$ in surface depth after emery paper grinding in order to reduce the effect of worked layer and for better surface damage observation. The observation of fatigue damage development and the measurement of surface crack length were conducted under a scanning electron microscope (SEM) or under an optical microscope by using plastic replica technique. Surface crack length, $l$, was measured in circumferential direction. To monitor crack growth behavior, specimens with a blind hole of $0.3 \mathrm{~mm}$ in both diameter and depth at center section were used and the diameter of the hole was included in the measured crack length.

(a)

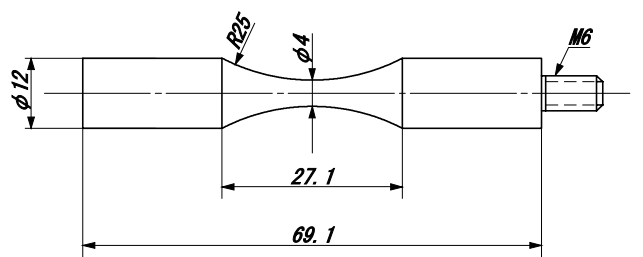

(b)

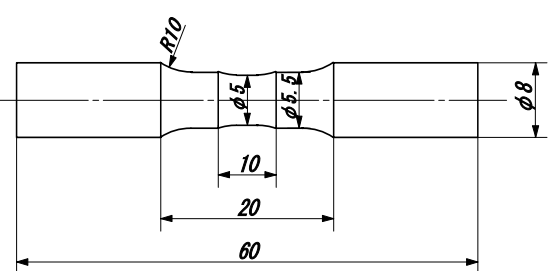

Fig. 1 Schematic geometry showing (a) ultrasonic and (b) rotating bending fatigue specimens 
The testing machines employed were a $19.5 \mathrm{KHz}$ piezoelectricity actuated ultrasonic fatigue system developed in our group, and an Ono-type rotating bending fatigue machine with a capacity of $100 \mathrm{Nm}$, operating at $50 \mathrm{~Hz}$. Fatigue experiments were carried out at room temperature and stress ratio of $R=-1$, in laboratory atmosphere or in nitrogen gas environment. To minimize a temperature rise induced by internal friction, ultrasonic fatigue tests were performed in a pulse-pause manner with a pulse length of $1 \mathrm{~s}$ and pause time of $5 \mathrm{~s}$. The maximum temperature rise was less than $3^{\circ} \mathrm{C}$ during the ultrasonic fatigue process. The details of the ultrasonic fatigue and rotating bending fatigue tests can be found in the literatures ${ }^{(10),(16)-(18)}$. Fatigue experiments in the nitrogen gas environment were conducted within a vinyl chamber in which nitrogen gas of at least $99.995 \%$ purity was supplied with the contents of oxygen and water vapor controlled below $5 \mathrm{ppm}$ and $10 \mathrm{ppm}$, respectively.

\section{Results and Discussion}

\subsection{Fatigue Strength}

Figure 2 shows $S$ - $N$ curves under ultrasonic (U) and rotating bending (R.B) fatigue, in which the data of plain specimens also included ${ }^{(16)}$. In case of plain specimens, fatigue life is longer under ultrasonic fatigue than under rotating bending fatigue. Similar tendency can be seen in the drilled specimens, though the effect of ultrasonic frequency on fatigue life is less remarkable. This is comprehensible when taking into account stress gradient occurred under rotating bending.

\subsection{Fatigue Crack Growth Behavior}

Figure 3 presents two kinds of crack propagation paths observed in (a) ultrasonic fatigue and (b) rotating bending fatigue. Fracture morphology of a drilled specimen is demonstrated in Fig. 3(c), too. As reported previously ${ }^{(16)}$, crack growth under rotating bending fatigue was mostly tension stress dominated whereas under ultrasonic fatigue, crack growth mode changed from tension to shear after extending some distance vertically to stress axis. The angle between cracks growing under shear mode and the stress axis is $\sim 35$ degrees, irrespective of the existence of the blind hole and the applied stress levels.

Figure 4 shows fracture morphologies observed in a drilled specimen failed under ultrasonic fatigue. Differing from the striations featured fracture observed in rotating bending fatigue of the alloy ${ }^{(16)}$, striations can merely be found in the narrow region related to tension mode crack growth. In the shear mode crack growth area, however, facets and characteristic voids distributed on the facets are of particular interests, which were seldom observed in rotating bending fatigue.

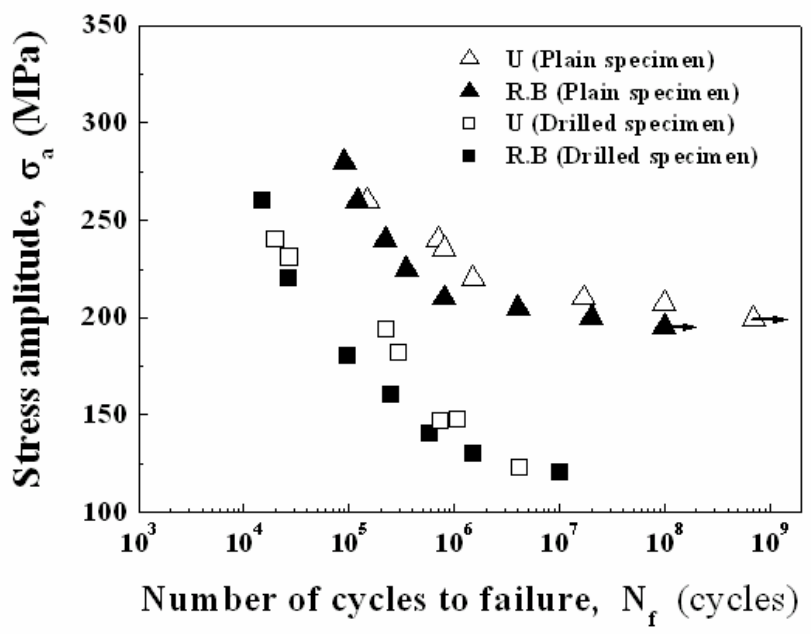

Fig. $2 S$ - $N$ curves in ambient air 


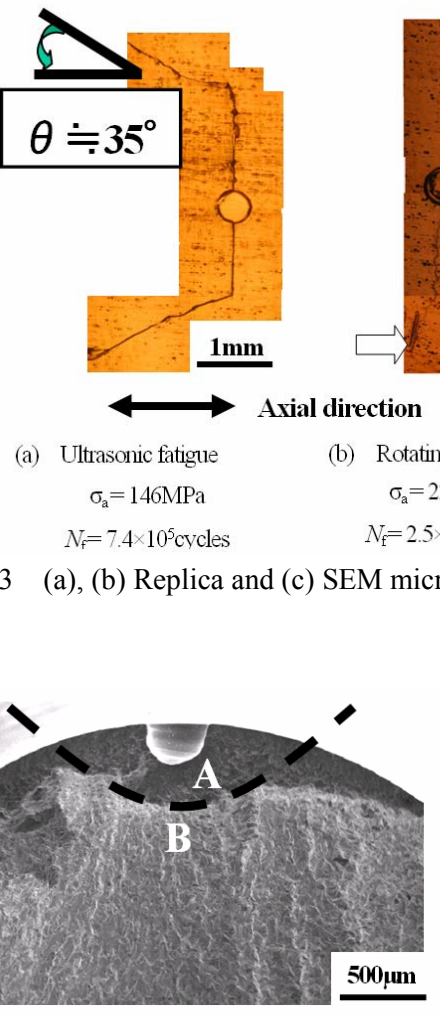

(a) Whole view

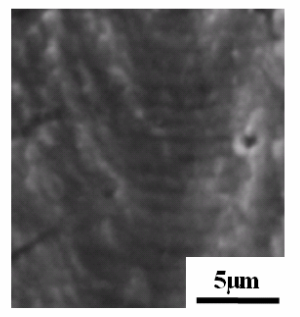

(b) PartAin (a)

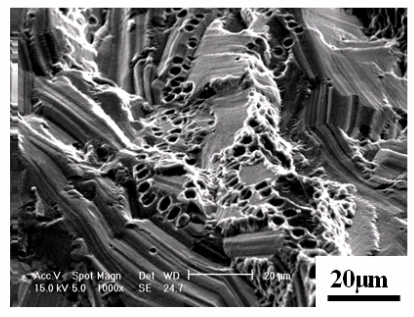

(c) PartBin (a)

Fig. 4 SEM micrographs showing fracture morphology under ultrasonic fatigue in ambient air

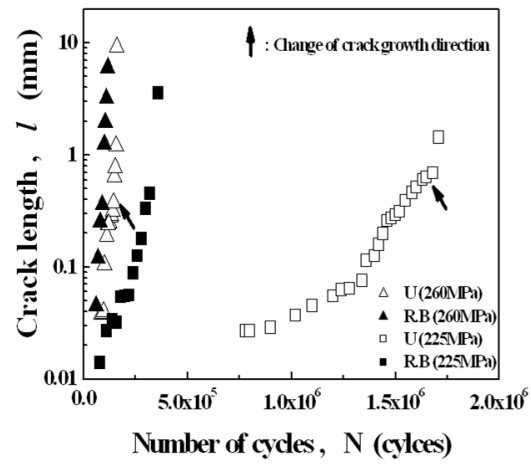

Fig. 5 Crack growth curves in ambient air

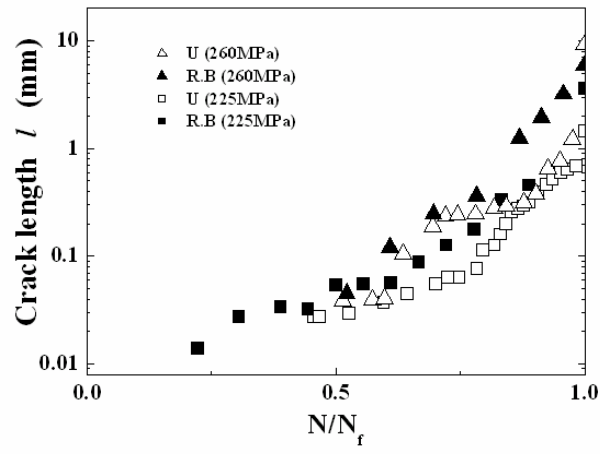

Fig. 6 Crack length vs. life ratio in ambient air

The effect of ultrasonic frequency on crack initiation and crack growth behavior was investigated by using plain specimens. In the present study, crack length was defined as projection length to the circumferential direction on the surface, because surface crack length was closely correlated with crack depth (Fig. 4(a)). Fig. 5 shows the crack growth as a function of loading cycles. Arrows in Fig. 5 indicate the occurrence of crack growth transition on the surface. Significant delay is recognized in the crack initiation and early crack growth in ultrasonic fatigue. As seen in Fig. 6, in which loading cycles are normalized by failure life, cracks initiate during the early fatigue stage of $\sim 20-40 \%$ of life and the majority of fatigue life is spent to grow the cracks up to $\sim 1 \mathrm{~mm}$, irrespective of the loading frequency. Therefore, it is considered that the main reason for the life extension in ultrasonic fatigue may be due to the suppression of crack initiation and early crack propagation. 
Figure 7 shows the relationship between crack growth rate and stress intensity factor range, $\Delta K$, which was approximated by

$$
\Delta K=\frac{2}{\pi} \Delta \sigma_{a} \sqrt{\frac{\pi l}{2}}
$$

where $\sigma_{\mathrm{a}}$ is the maximum nominal stress amplitude at net area with the blind hole neglected. In case of ultrasonic fatigue, $\sigma_{\mathrm{a}}$ was determined by displacement at free end of specimen ${ }^{(10)}$. The aspect ratio of crack depth to surface crack length was $\sim 0.4$ for cracks propagating in tension mode under rotating bending fatigue. The aspect ratio of the plain specimen in ultrasonic fatigue, however, differed slightly from the drilled specimen (Fig. 4), and was uncertain due to complex fracture morphology after crack growth transition (Fig. 12). For the convenience of $\Delta K$ calculation, therefore, a half of surface crack length was employed. Crack growth data obtained for long cracks under ultrasonic fatigue ${ }^{(17)}$, included for comparison with the mean crack growth rate under rotating bending fatigue and ultrasonic fatigue represented by dashed and solid lines, respectively.

It is seen that a crack propagates slower under ultrasonic fatigue than under rotating bending fatigue for lower $\Delta K$ less than a critical value in the range of 6-8 $\mathrm{MPa} \sqrt{m}$. However, cracks grow faster under ultrasonic fatigue at larger $\Delta K$, e.g. $\Delta K>6-8 \mathrm{MPa} \sqrt{m}$. In case of ultrasonic fatigue, it is interesting that short cracks propagate below the threshold of stress intensity factor range determined for long cracks ${ }^{(17)}, \Delta K_{\mathrm{th}}=\sim 2.8 \mathrm{MPa} \sqrt{m}$, and grow faster than long cracks in the range of $2.8<\Delta K<6-8 \mathrm{MPa} \sqrt{m}$. Similar short crack behavior is found in conventional fatigue.

As arc-marked in Fig. 4(a), crack morphology related to tension mode growth (part A) is totally different from that under shear mode growth (part B), so that crack depth corresponding to the crack growth transition is of mechanical significance in the ultrasonic fatigue of the alloy. In Fig. 8, the crack depth at transition point is plotted as a function of the stress amplitude applied. The lower the stress applied, the deeper the crack depth at transition point. In fact, the relation between the crack depth at transition point and the stress applied can be approximated as

$$
\sigma_{a}^{n} b_{T}=C
$$

where $b_{\mathrm{T}}$ is the crack depth at transition point, $n$ and $C$ are constants depending on material properties and loading conditions, implying that there exists a mechanical criterion which determines the growth mode transition under ultrasonic fatigue.

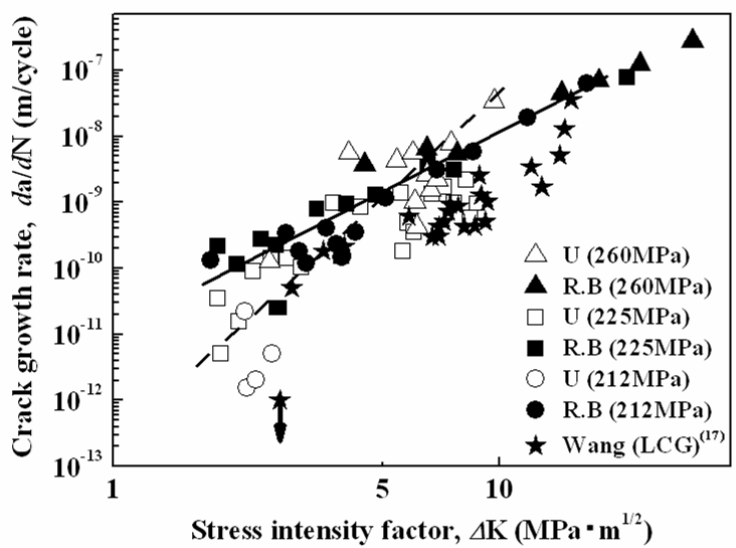

Fig. 7 Crack growth rate as a function of stress intensity factor range, $\Delta K$ 
Figure 9 shows the relation between the stress intensity factor range at transition point, $\Delta K_{\mathrm{T}}$, and ultrasonic fatigue life, $N_{\mathrm{f}}$, in which $\Delta K_{\mathrm{T}}$ was determined by the method described in reference ${ }^{(19)}$ and using a crack depth, instead. Although $\Delta K_{\mathrm{T}}$ fluctuates to some extent in case of the drilled specimens, it converges to $8 \mathrm{MPa} \sqrt{m}$ irrespective of fatigue life. This constant $\Delta K_{\mathrm{T}}$ agrees well with the fact that the critical crack length/depth corresponding to crack growth mode transition increased with decreasing cyclic stress level.

As mentioned above, fatigue life was longer under ultrasonic fatigue than under rotating bending fatigue, which is a definite effect of loading frequency on the fatigue life of Al alloy 7075-T6. Meanwhile, surface observation suggests that the suppression of crack initiation as well as the early propagation of small cracks should be related to the extension of fatigue life under ultrasonic fatigue (Fig.5). The increase in flow stress of materials subjected to high strain rate cycling ${ }^{(20)}$, might be a possible explanation. On the other hand, the transition of crack growth mode from tension to shear may be correlated to the characteristic microstructure of crystal clusters formed during the extrusion process of the alloy, because the macroscopic crack extension under shear mode was $\sim 35$ degrees against the stress axis or extrusion direction, which agrees well with the angle of 35.7 degrees formed between slip planes $\{111\}$ and extrusion planes $\{110\}$ along the axial direction ${ }^{(21)}$. This is true because numerous voids initiated from precipitates were observed on specific planes and facets (Fig. 4(c)), and that precipitates preferred to distribute on the planes $\{111\}$ and $\{110\}^{(22)}$.

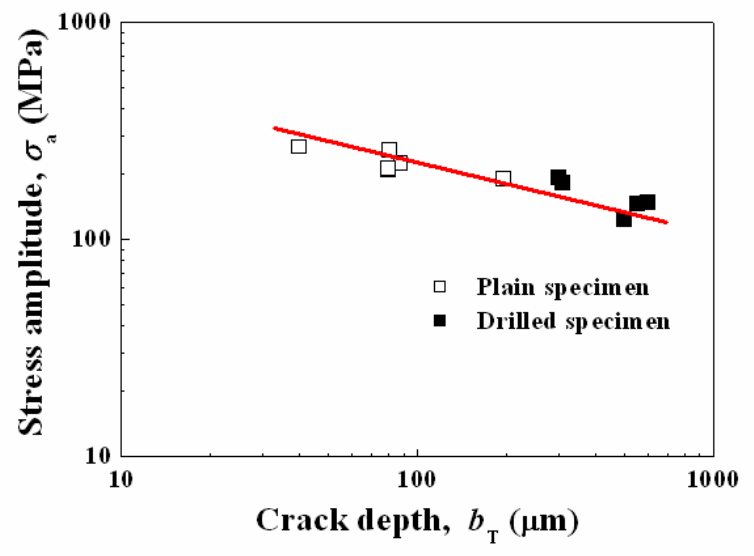

Fig. $8 \sigma_{\mathrm{a}}$ as a function of $b_{\mathrm{T}}$ in ambient air

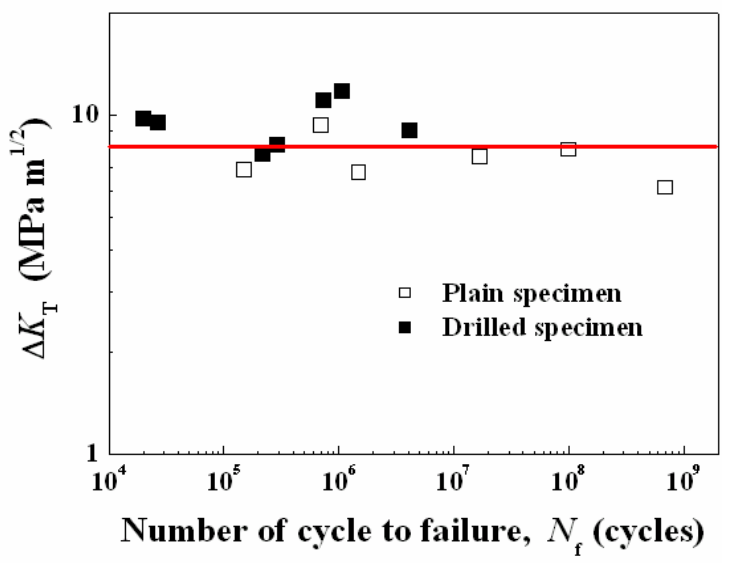

Fig. $9 \Delta K_{\mathrm{T}}$ as a function of $N_{\mathrm{f}}$ in ambient air 
The transition of crack growth from tension mode to shear mode was well investigated for extruded Al alloys, and it was reported that the transition may take place if the crack tip plasticity region reaches 4 times as large as the grain size ${ }^{(23)(24)}$. Actually, the nearly constant $\Delta K_{\mathrm{T}}$ (Fig. 8) implies the existence of such a mechanical condition for the growth mode transition occurred in the conditions of present study. However, it is difficult by using only a mechanical parameter, $\Delta K_{\mathrm{T}}$, to explain the reason why this kind of crack growth transition did not occur in the rotating bending fatigue of the alloy in air. Other effects besides $\Delta K_{\mathrm{T}}$, e.g. environmental influence, have to be taken into account.

It is well known that the diffusion of oxygen and moisture and the surface reaction kinetics ahead of crack tips are time dependent. Therefore, the effects of ambient air on crack propagation behavior at ultrasonic frequency are controlled by the crack growth rate under the competition between the advance of crack tip per cycle and the distance reachable by oxygen and moisture molecules during a cycle. In ultrasonic fatigue, for instance, the cyclic opening and closure behavior at crack tip in ambient air can be quite similar to that in vacuum, provided that crack growth rate exceeds the diffusion speed of moisture molecules so as to avoid them from getting into fresh surfaces at crack tip ${ }^{(25)(26)}$. In case of Al alloys, the cutoff crack growth rate was found to be $\sim 3 \times 10^{-9} \mathrm{~m} / \mathrm{c}^{(27)}$. As seen in Fig. 7, crack growth rates associated with the critical stress intensity factor range at transition point in ultrasonic fatigue, i.e. $\Delta K=\sim 8 \mathrm{MPa} \sqrt{m}$, fall in the range of $2-3 \times 10^{-9} \mathrm{~m} / \mathrm{c}$, which agrees well to the above-mentioned cutoff rate. On the other hand, similar sharp change in crack paths, as seen in the ultrasonic fatigue (Fig. 3(a)), was also observed in the rotating bending fatigue of extruded $\mathrm{Al}$ alloys in a condition lacking in oxygen and moisture ${ }^{(28)}$ as well as in oil environment ${ }^{(29)}$. As a matter of fact, crack growth paths changed sharply from nearly vertical to stress axis to oblique approximately 35 degrees to the stress axis ${ }^{(29)}$. It is clear that environment at crack tip, especially the absorption of oxygen and moisture during each loading cycle, become a key factor to determine the crack growth transition of Al alloys in lab atmosphere. In other words, the differences in crack growth behavior and fracture mechanism of $\mathrm{Al}$ alloys between ultrasonic fatigue and rotating bending fatigue, are eventually crack tip environment dependent, in the sense that cracks propagating in tension mode by interacting with oxygen and moisture in ambient air will change to shear mode growth and behavior similarly as in vacuum environment, as long as crack grow rate exceeds the critical value of $\sim 3 \times 10^{-9} \mathrm{~m} / \mathrm{c}$.

Figure 10 shows $S$ - $N$ curves of plain specimens fatigued in nitrogen environment. In Fig. 10, the results obtained in ambient air are represented by lines for comparison. The prominent life dependence on loading frequency as observed in ambient air environment diminishes in the fatigue in nitrogen gas.

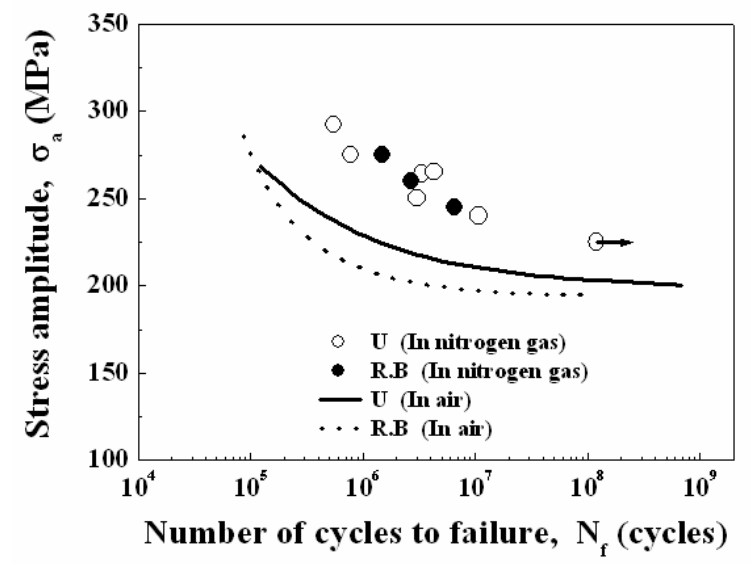

Fig. $10 S-N$ curves in nitrogen gas 
Furthermore, fatigue strength increases significantly in nitrogen gas than in air, irrespective of loading frequency. Some fatigue experiments in nitrogen gas were interrupted after stress cycling beyond the fatigue life of plain specimens failed in air. Crack initiation, however, was not recognized on the surface of either ultrasonic or rotating bending fatigued specimens. Considering the facts that crack nucleation seldom happened before $\sim 40 \%$ of total life in the fatigue of the alloys in air (Fig. 6), a delay in fatigue crack nucleation may be the main reason that gives rise to the large life extension under both ultrasonic and rotating bending fatigue in nitrogen gas.

Usually, variation of surface energy due to moisture and oxygen absorption is considered to affect crack initiation. In the present study, the exactly same surface treatment was carried out for the specimens prior to fatigue in nitrogen gas as in air, so that the influence of initial surface conditions, e.g. moisture and oxygen absorption, on fatigue slip deformation as well as crack nucleation in nitrogen gas would not differ meaningfully from that in ambient air. Further research, however, is necessary to clarify surface energy variation during stress cycling in nitrogen gas and the main causes that led to crack initiation suppression in both ultrasonic and rotating bending fatigue in nitrogen gas.

Crack morphology and fracture micrographs are shown in Figs. 11 and 12 for the specimens fatigued in nitrogen gas, respectively. In case of ultrasonic fatigue, crack growth changed from tension mode to shear one in nitrogen gas as observed in ambient air. However, the crack advance under tension mode is much shorter, and the striations are less recognized in nitrogen gas than in ambient air. In case of rotating bending fatigue, however, shear mode crack growth that was not observed in ambient air happened obviously in nitrogen gas with almost the same inclination of $\sim 35$ degrees to the stress axis as seen in ultrasonic fatigue. Furthermore, the influence of loading frequency on the shear mode fracture of the $\mathrm{Al}$ alloy was not recognized in nitrogen gas.

As seen in Fig. 10, the fatigue strength of the plain specimens in ambient air is higher in ultrasonic fatigue than in rotating bending fatigue. The main reason for the strength increase in ultrasonic fatigue was considered to be due to flow stress rise during high strain rate deforming such that crack initiation in ultrasonic fatigue was significantly suppressed. Similar trend would have appeared in the fatigue of the alloy in nitrogen gas, in which no difference in the life was found between ultrasonic and rotating bending fatigue. Stress gradient in rotating bending fatigue, which lightened remarkably damage degree in the vicinity of small cracks, is considered as a primary factor that can cancel the life extension induced by the increased flow stress in ultrasonic fatigue.

Consequently, the transitions in crack growth mode as well as in fracture mechanism of the $\mathrm{Al}$ alloy can occur in both ultrasonic fatigue and rotating bending fatigue, depending not only on the mechanical relation between crack tip plasticity field and grain size but also on

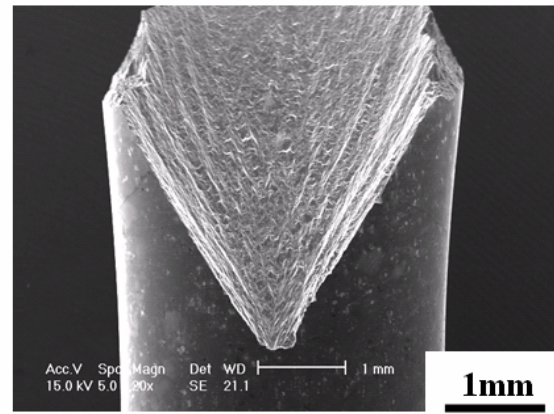

(a) Ultrasonic fatigue

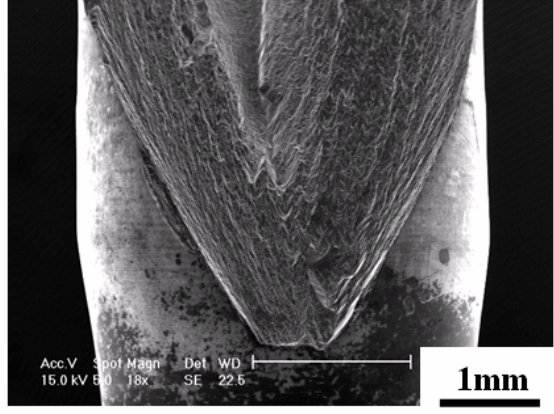

(b) Rotating bending fatigue

$\left(\sigma_{\mathrm{a}}=265 \mathrm{MPa} \quad \mathrm{N}_{\mathrm{f}}=4.30 \times 10^{6}\right.$ cycles $)$

Fig. 11 SEM micrographs showing fatigue crack morphology in nitrogen gas 
the competition between crack extension per cycle and the diffusion rate of oxygen and moisture into crack tips. The latter is more important.

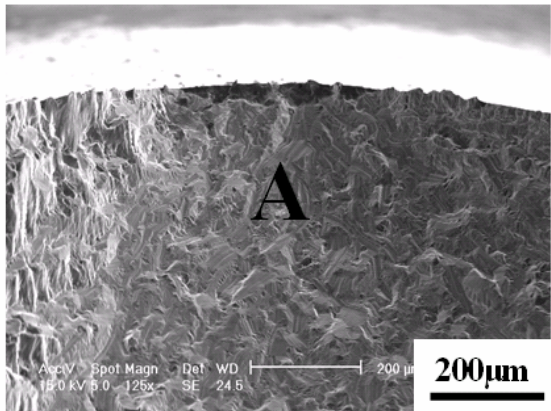

(a-1) Whole view

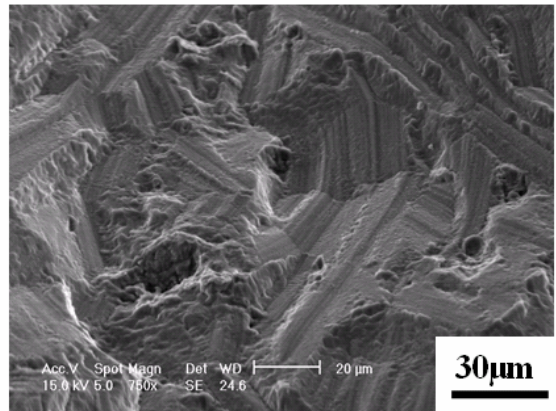

(a-2) Part A in (a-1)

(a) Ultrasonic fatigue $\left(\sigma_{\mathrm{a}}=265 \mathrm{MPa}, N_{\mathrm{f}}=4.30 \times 10^{6}\right.$ cycles $)$

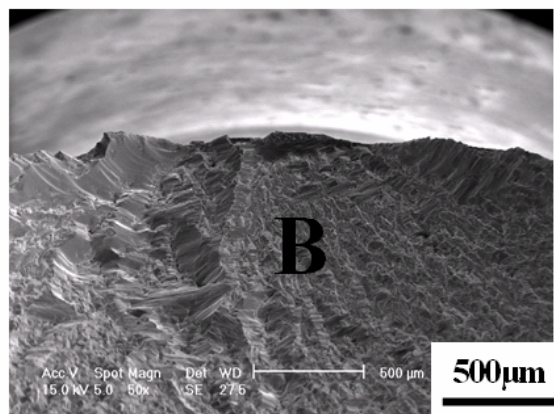

(b-1) Whole view

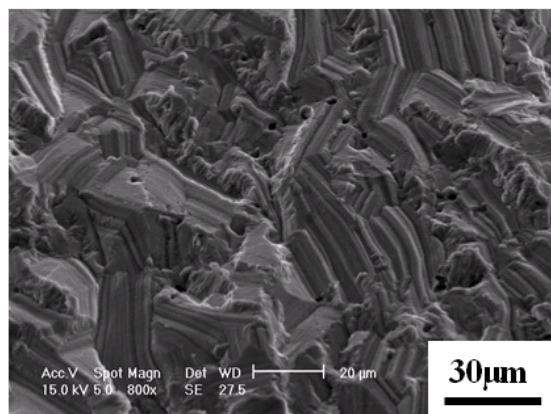

(b-2) Part B in (b-1)

(b) Rotating bending fatigue ( $\sigma_{\mathrm{a}}=245 \mathrm{MPa}, N_{\mathrm{f}}=6.57 \times 10^{6}$ cycles $)$

Fig. 12 SEM micrographs showing fracture morphology under (a) ultrasonic and (b) rotating bending fatigue in nitrogen gas

\section{Conclusions}

Ultrasonic and rotating bending fatigue experiments were carried out with Al alloy 7075-T6 at room temperature in ambient air and in nitrogen gas. Fatigue crack growth behavior and fracture mechanism involved were investigated and the effects of loading frequency were examined from the viewpoints of environment and microstructure. The following results are obtained.

In case of fatigue in ambient air condition:

(1) Fatigue life was longer in ultrasonic fatigue than in rotating bending fatigue.

(2) Differing from the tension mode dominated failure in rotating bending fatigue, crack growth in ultrasonic fatigue changed macroscopically from tensile mode characterized by striations to shear mode featured by facets.

(3) The direction of macroscopic shear mode crack propagation inclined $\sim 35$ degrees to the stress axis.

(4) In ultrasonic fatigue, the crack depth at the crack growth transition point increased with decrease in loading stress. The relation can be approximated as $\sigma_{a}^{n} b_{T}=C(n \approx 4)$. The cutoff crack growth rate at transition point was found to be $\sim 3 \times 10^{-9} \mathrm{~m} / \mathrm{c}$ and the associated critical stress intensity factor range was $\sim 8$ $\operatorname{MPa} \sqrt{m}$.

(5) Cracks grew slower in ultrasonic fatigue than in rotating bending fatigue before 
the transition happened, but it grew faster after the transition.

In case of fatigue in nitrogen gas condition:

(1) The difference in fatigue life between ultrasonic and rotating bending fatigue decreased and was less remarkable than in ambient air condition.

(2) Crack growth in ultrasonic fatigue changed similarly from tensile mode to shear mode as in ambient air.

(3) Macroscopic shear mode crack growth transition happened in rotating bending fatigue with almost the same inclination of $\sim 35$ degrees to the stress axis as seen in ultrasonic fatigue.

(4) Environment, e.g. the diffusion of moisture and oxygen at crack tip, played an important role in the macroscopic shear mode crack growth transition of the alloy. The direction of macroscopic shear mode crack growth has a close relation with the texture of the alloy.

\section{Acknowledgments}

Partial support from the Japan Society for the Promotion of Science under Grant-in-Aid (C) (No. 13650096) is gratefully acknowledged. Special thanks are due to Mrs. N. Yoneyama, T. Arima, K. Yoshinaga and K. Hagiwara for their technical supports, and to Prof. D. Grant for English grammar revision.

\section{References}

(1) Shiozawa, K. et al., Subsurface Fatigue Crack Initiation Behavior and S-N Curve Characteristics in High Carbon-Chromium Bearing Steel, Journal of the Society of Materials Science, Japan, Vol.48, No.10 (1999), pp.1095-1100.

(2) Murakami, Y. et al., Mechanism of Superlong Fatigue Failure in the Regime of $N>10^{7}$ Cycles and Fractography of the Fracture Surface, Transactions of the Japan Society of Mechanical Engineers, Series A, Vol.66, No.642 (2000), pp.311-319.

(3) Sakai, T. et al., S-N Property and Fractography of High Carbon Chrominum Bearing Steel over Ultra Wide Life Region under Rotating Bending, Transactions of the Japan Society of Mechanical Engineers, Series A, Vol.67, No.663 (2001), pp.1805-1812.

(4) Wang, QY. et al., Effect of Inclusion on Subsurface Crack Initiation and Gigacycle Fatigue Strength, International Journal of Fatigue, Vol.24 (2002), pp.1269-1274.

(5) Bathias, C., There is no Infinite Fatigue Life in Metallic Materials, Fatigue \& Fracture of Engineering Materials \& Structures, Vol.22 (1999), pp.559-565.

(6) Marines, I. et al., Ultrasonic Fatigue Tests on Bearing Steel AISI-SAE 52100 at Frequency of 20 and $30 \mathrm{kHz}$, International Journal of Fatigue, Vol.25 (2003), pp.1037-1046.

(7) Stanzl-Tschegg, S.E. Mayer, H., Fatigue and Fatigue Crack Growth of Aluminum Alloys at Very High Number of Cycles, International Journal of Fatigue, Vol.23 (2001), pp.s231-s237.

(8) Furuya, Y. et al., Effect of Frequency on Giga-Cycle Fatigue Properties for Low-Temperature-Tempered SNCM439 Steel, Transactions of the Japan Society of Mechanical Engineers, Series A, Vol.68, No.667 (2002), pp.477-483.

(9) Takeuchi, E. et al., Effect of Frequency on Giga-Cycle Fatigue Properties for Ti-6Al-4V Alloy, Transactions of the Japan Society of Mechanical Engineers, Series A, Vol.70, No.696 (2004), pp.1124-1130.

(10) Chen, Q. et al., Ultrasonic Fatigue Properties of Ni-Base Superalloy, Transactions of the Japan Society of Mechanical Engineers, Series A, Vol.69, No.679 (2003), pp.626-632.

(11) Chen, Q. et al., Ultrasonic Fatigue Properties of Inconel 718 at Elevated Temperature, Proceedings of the Mechanical Engineering Congress No.05-1, Vol.1 (2005), pp.213-214. 
(12) Endo, K., Komai, K., Environmental Effects on Initiation and Propagation of Fatigue Cracks in High Strength Steel, Transactions of the Japan Society of Mechanical Engineers, Series A, Vol.42 No.361 (1976), pp.1800-1806.

(13) Wei, R.P. et al., Fracture Mechanics and Surface Chemistry Studies of Fatigue Crack Growth in an Aluminum Alloy, Metallurgical Transactions, 11A (1980), pp.151-158.

(14) Goto, M. et al., Fatigue Behavior of Smooth Specimen Cut from Squeeze Cast Al Alloy Car Wheel and Effect of Stress Change, Journal of the Society of Materials Science, Japan, Vol.50, No.11 (2001), pp.1269-1275.

(15) Nagano, T. et al., Influence of Reversion Austenite on Initiation and Propagation of Fatigue Crack of Maraging Steel, Transactions of the Japan Society of Mechanical Engineers, Series A, Vol.69, No.679 (2003), pp.633-639.

(16) Kawagoishi, N., et al., Ultrasonic Fatigue Properties of a High Strength Extruded Al Alloy, Transactions of the Japan Society of Mechanical Engineers, Series A, Vol.69, No.688 (2003), pp.1672-1677.

(17) Wang, QY., et al., Effect of Pitting Corrosion on Very High Cycle Fatigue Behavior, Scripta Materialia, Vol.48 (2003), pp.9-14.

(18) Nisitani, H. et al., Comparison of Characteristics of Crack Growth in Three Age-Hardened Al Alloy, Transactions of the Japan Society of Mechanical Engineers, Series A, Vol.51, No.464 (1985), pp.1017-1025.

(19) Nisitani, H., Chen, D-H., Stress Intensity Factor for a Semi-Elliptic Surface Crack in a Shaft under Tension, Transactions of the Japan Society of Mechanical Engineers, Series A, Vol.50, No.453 (1984), pp.1077-1083.

(20) Miura, K. et al., Influence of Strain Rate on Grain Size Dependence of Strength of Sheet Steel, Journal of the Society of Materials Science, Japan, Vol.47, No.10 (1998), pp.1053-1058.

(21) The Japan Society of Materials Science ed., Materials, Mechanical Properties and Testing Methods (in Japanese), 1981, p.55.

(22) The Japan Society of Light Metals ed., Microstructures and Properties of Aluminums (in Japanese), 1991, p.302.

(23) Birkbeck, G. et al., Aspects A stage II Fatigue Crack Propagation in Low-Carbon Steel Journal of Materials Science, Vol.6 (1971), pp.319-323.

(24) Koterazawa, R., Shimo, D., Fatigue Crack Propagation and Crystallographic Orientation of an Aluminum Alloy, Journal of the Society of Materials Science, Japan, Vol.25, No.273 (1976), pp.535-541.

(25) Ricker, R.E., Duqette, D.J., The Role of Hydrogen in Corrosion Fatigue of High Purity Al-Zn-Mg Exposed to Water Vapor, Metallurgical Transactions, Vol.19A (1988), pp.1775-1783.

(26) Tien, J.K., Gamble, R.P., The Room Temperature Fatigue Behavior of Nickel-Base Superalloy Crystal at Ultrasonic Frequency, Metallurgical Transactions, Vol.2 (1971), pp.1933-1938.

(27) Holper, B. et al., Near Threshold Fatigue Crack Growth in Aluminum Alloys at Low and Ultrasonic Frequency: Influences of Specimen Thickness, Strain Rate, Slip Behavior and Air Humidity, International Journal of Fatigue, 25 (2003), 397-411.

(28) Okada, T. et al., Cup and Cone Fracture and Environmental Fatigue Strength of High Tensile-Strength Aluminum Alloys, Journal of the Society of Materials Science, Japan, Vol.31, No.343 (1982), pp.383-389.

(29) Kawagoishi, N., Nisitani, H., Relation Between Fatigue Strength and Crack Morphology of Age-Hardened Al Alloys in an Oil Environment, Transactions of the Japan Society of Mechanical Engineers, Series A, Vol.55, No.512 (1989), pp.703-709. 